\title{
"É tempo de morangos": argumentação, discurso e enunciação em A hora da estrela, de Clarice Lispector
}

\section{"It's strawberry time": argumentation, discourse and enunciation in Clarice Lispector's A hora da estrela ${ }^{1}$}

Artigo originalmente apresentado na forma de comunicaçao no simposio "Argumentaçăo, Língua, Discurso", coordenado pelas Profas. Dras. Mônica Zoppi--ontana e Sheila Elias de Oliveira, durante o sobre Discurso y Argumentación) entre os dias 14 e 16 de março de 2018, na Universidade de Buenos Aires. Artigo produzido como atividade de pesquisa de pós-doutorado "A angústia que (nao) se enuncia: um pensamento do feminino, sob supervisão da Profa. Dra. Carla Rodrigues, no Pós Pos-doutorando com o projeto de pesquisa entre Butler e Pêcheux no estudo discursivo do funcionamento da linguagem", sob supervisão da Profa. Livre Docente Mônica Graciela ZoppiFontana, no Instituto de Estudos da Linguagem UNICAMP e no Grupo de Pesquisa Muheres em Discurso.

orcid. org/0000-0001-9495-517

E-mail: jacob.biziak@ifpr.edu.br
Jacob do Santos Biziak ${ }^{2}$

Instituto Federal do Paraná, Campus Palmas, Colegiado de Letras, Palmas, PR, Brasil.

RESUMO: Esta proposta de trabalho justifica-se à medida que coloca a obra de Clarice Lispector em um novo contexto citacional, ainda mais se levarmos em conta, também, o quanto o "pensamento do feminino" (proposto por Carla Rodrigues em diálogo com a obra de Jacques Derrida), aqui, surge sob novas condições de linguagem, enveredando pelo plano temático e pela atualização discursiva dos enunciadores. Enquanto objetivo central, fortaleceremos o emprego de "enunciador", não de "narrador", como dispositivo de leitura da diegese, uma vez que destaca a questão da interpelação e do posicionamento da instância enunciadora diante da textualização discursiva, dando-lhe dimensão ideológica e argumentativa. Ou seja, propõe-se entender este "pensamento do feminino" como prática política diante da realidade, da circulação de verdades e da sociedade; o que, pela perspectiva do funcionamento discursivo, ajuda a pensar a ficção de Lispector como comprometida com o social, ainda que nem sempre pela via explícita, prática tão comum em boa parte do tempo em que a autora produziu e publicou.

Palavras-chave: Argumentação; Enunciação; Pensamento do feminino; A hora da estrela.

ABSTRACT: This study is explained by the fact that it places the work of Clarice Lispector in a new reference context, especially if we take into account also how the "female thought" (proposed by Carla Rodrigues in dialogue with the work of Jacques Derrida), here, arises under new conditions of language, going through the thematic plan and the updated discurse of the enunciators. As a central objective, we will strengthen the use of "enunciator", not "narrator", as a device for reading diegese, since it highlights the question of the interpellation and position of the enunciating instance before the discursive textualization, giving it ideological and argumentative dimension. That is, it is proposed to understand this "female thought" as a political practice before reality, the circulation of truths and society; which, from the perspective of the discursive functioning, helps us to think about Lispector fiction committed to the social, although not always by a explicit way, practice so common during most of the time when the author produced and published.

Keywords: Argumentation; Enunciation; Feminine thought; $A$ hora da estrela. 
É. Eu me acostumo mas não amanso. Por Deus! eu me dou melhor com os bichos do que com gente. Quando vejo o meu cavalo livre e solto no prado - tenho vontade de encostar meu rosto no seu vigoroso e aveludado pescoço e contar-lhe a minha vida. E quando acaricio a cabeça de meu cão - sei que ele não exige que eu faça sentido ou me explique.

Talvez a nordestina já tivesse chegado à conclusão de que a vida incomoda bastante, alma que não cabe bem no corpo, mesmo alma rala como a sua. Imaginavazinha, toda supersticiosa, que se por acaso viesse alguma vez a sentir um gosto bem bom de viver - se desencantaria de súbito de princesa que era e se transformaria em bicho rasteiro. Porque, por pior que fosse sua situação, não queria ser privada de si, ela queria ser ela mesma. Achava que cairia em grave castigo e até risco de morrer se tivesse gosto. Então defendia-se da morte por intermédio de um viver de menos, gastando pouco de sua vida para esta não acabar. Essa economia lhe dava alguma segurança pois, quem cai, do chão não passa. Teria ela a sensação de que vivia para nada? Nem posso saber, mas acho que não. Só uma vez se fez uma trágica pergunta: quem sou eu? Assustou-se tanto que parou completamente de pensar. Mas eu, que não chego a ser ela, sinto que vivo para nada. Sou gratuito e pago as contas de luz, gás e telefone. Quanto a ela, até mesmo de vez em quando ao receber o salário comprava uma rosa. Tudo isso acontece no ano este que passa e só acabarei esta história difícil quando eu ficar exausto da luta, não sou um desertor.

epígrafe anterior textualiza algumas considerações do enunciador de

A hora de estrela (2017) a respeito das (im)possibilidades de sentidos para a existência. Usamos dessa passagem para começar a demarcar o que entendemos como nosso gesto de leitura, tentando concatenar Derrida e Pêcheux em direção a um estudo do processo de construção de certa argumentação (principalmente a respeito da construção da narrativa, da enunciação e da personagem central, Macabéa) na referida obra.

Dessa maneira, o que pretendemos é empreender um processo de interpretação que entende o sentido não como essência a ser alcançada

${ }_{1}^{1}$ Lispector, Clarice. A hora da estrela: edição com manuscritos e ensaios inéditos. Rio de Janeiro: Rocco, 2017. p. 64-5. enquanto verdade oculta, escondida, decodificada, no interior da narrativa. Ao contrário, ao mesmo tempo em que entendemos o sentido como instável e marcado por um jogo de presença e ausência (DERRIDA, 2013, 1971 e 1997), defendemos que tal posicionamento deve ser considerado, também, mediante o caráter material da significação (PÊCHEUX, 1988). Assim, propomos o uso de dispositivos de leitura que assumam um caráter discursivo de interpretação da literatura.

Começamos isso ao considerar o conceito de enunciador no lugar de narrador para a leitura da novela de Lispector (2017). Isso, entre outros motivos, acontece por entendermos o "sentido" como um processo interminável de significação, o qual é afetado pela maneira como o enunciador se relaciona com a forma-sujeito (PÊCHEUX, 1988):

O dizer não é propriedade particular. As palavras não são nossas. Elas significam pela história e pela língua. 0 que é dito em outro lugar também significa em "nossas" palavras. O sujeito diz, pensa que sabe o que diz mas não tem acesso ao controle sobre o modo pelo qual os sentidos se constituem nele (ORLANDI, 2000).

Dessa maneira, o lugar do sujeito em uma formação discursiva não é vazio, mas preenchido por um Sujeito do Saber que, por relação com a ideologia e a história, cria a aparência de neutralidade e obviedade para os sentidos. Interpelado pela formação discursiva, o enunciador entende-se como sujeito e origem de seu dizer, fazendo recurso à memória discursiva que lhe estabelece as (im)possibilidades de atualização dos discursos. Isso, em larga medida, revê aquilo que alguns importantes teóricos estruturalistas da diegese, outrora, propuseram sobre a interpretação da ficção.

É o caso, por exemplo, de Gerard Genette (s.n.). Este, em sua importante obra Discurso da narrativa, defende um método de estudo da constituição das diegeses por meio da instância do narrador, o que se desdobraria nas formas de homo, hetero e autodiegético, dependendo da maneira como se 
dá a relação com o foco narrativo; ou seja, a perspectiva assumida para se construir a ficção. A importância desta obra teórica consiste, principalmente, em trazer um entendimento de que não existe nenhuma possibilidade de uma narrativa construir um relato isento de relação com a realidade que está propondo como "natural e óbvia". No entanto, tal consideração não é feita levando-se em conta a dimensão material de tais procedimentos de construção de uma representação de realidades. Tanto isso ocorre que, no título, o termo "discurso" é tomado como o conjunto de mecanismos responsáveis por textualizar uma narrativa (algo como a figurativização de certos significados que seriam imanentes à obra), e não como efeitos de sentidos entre interlocutores, como propõe Pêcheux (1988).

Portanto, tomamos o enunciador como sujeito discursivo que, interpelado, fala de certo lugar e regido por uma formação discursiva, a qual constrói efeitos de evidência ao sujeito posicionado nela. Além disso, não podemos perder de vista que o processo de construção de leitura construído pelo enunciatário com a diegese também está subordinado ao que existe dele enquanto posição-sujeito:

Na passagem para o espaço teórico, [...] para o espaço discursivo, o lugar social que o sujeito ocupa numa determinada formação social e ideológica, que está afetada pelas relações de poder, vai determinar o seu lugar discursivo, através do movimento da forma-sujeito e da própria formação discursiva com a qual o sujeito se identifica (GRIGOLETTO, 2005, p. 158).

Com isso, a ideia relacional que Genette (s.n.) traz entre narrador, narração e narrativa não pode ser entendida mediante uma compreensão de uma realidade anterior ao dizer, livre do lugar social ocupado pelo sujeito. Além disso, este enunciador - uma vez interpelado como sujeito em um procedimento que é necessariamente simbólico - assumirá uma forma individual concreta, a qual - conforme nos lembra Lagazzi (1988) responderá como "sujeito de diretos", responsável e inserido na articulação social do Estado no capitalismo. A partir disso, podemos pensar, também, o funcionamento da ideologia:

É a ideologia que fornece as evidências pelas quais 'todo mundo sabe' o que é um soldado, um operário, um patrão, uma fábrica, uma greve, etc., evidências que fazem com que uma palavra ou enunciado 'queiram dizer o que realmente dizem' e que mascarem, assim, sob a 'transparência da linguagem', aquilo que chamaremos o caráter material do sentido das palavras e dos enunciados (PÊCHEUX, 1988, p. 160).

Quando pensamos no enunciador como operador de leitura do texto narrativo ${ }^{2}$, estamos pensando em um trabalho de intepretação que toma, então, os sentidos nem como óbvios nem como estáveis, a não ser como efeitos de evidência em uma formação discursiva. Além disso, trata-se de uma instância enunciativa na qual os esquecimentos operam de maneira a causar o efeito de que há uma realidade com quem podemos nos relacionar "desde sempre". Levar, portanto, isso em conta significa desestabilizar a significação e propor a mesma como atividade em hiância, na qual a subjetividade inscreve-se nos usos da língua, mas não livre e plenamente, já que subordinada a procedimentos que lhe escapam. Por meio dessa reflexão, o trabalho com a literatura é deslocado para um outro horizonte hermenêutico. Esse movimento de interpretação parece interessante à medida que também pode ser articulado com o que Derrida propõe em suas obras.

O pensador argelino - em Gramatologia (2013) e A escritura e a diferença (1971) - interroga o Estruturalismo de maneira a apontar uma metafísica do signo com a proposta de descontruir categorias do pensamento ocidental que, ao longo do tempo e pela repetição, acabaram sendo erguidas como

2 Tomar o enunciador como operador de leitura, aqui, em que construímos um gesto de leitura baseado na Análise do Discurso de Pêcheux, significa substituir uma crítica literária pautada pela análise de conteúdo por uma discursiva. 
verdades absolutas e instauradoras de hierarquias. Além disso, no trabalho com a literatura, essas questões podem ser especialmente trabalhadas. Sendo assim, como sintetiza Carla Rodrigues (2013a):

a literatura, em Derrida, aparece como aquilo que abala todos os limites, com sua qualidade de estar dentro/fora dos discursos sobre e da verdade. (...) e também o caminho pelo qual ele pensará sua crítica à metafísica como organizada pela hierarquia dos pares presença/ausência, dentro/ fora, interioridade/exterioridade. (...) Com a função de questionar a autoridade e a pertinência da pergunta "o que é", a literatura será para o filósofo uma estratégia de abalo de qualquer autoridade metafísica. Ou, retomando os termos iniciais, na literatura o signo não é necessariamente signo de. (p. 25-27, grifo da autora).

Entendemos, portanto, que, em certa medida, as propostas de reflexão de Pêcheux e Derrida podem ser aproximadas uma vez que permitem o estabelecimento de processos interpretativos de forma a questionar o aparentemente estabilizado: seja pela consideração do caráter material da linguagem; seja pela consideração de que as mais diversas textualidades podem ser postas em novas redes citacionais (ou seja, em novas possibilidades de uso e funcionamento de leitura antes não realizadas). Isso não significa arbitrariedade ou relativismo nas leituras; ao contrário: significa um trabalho ético com a linguagem, no qual a responsabilidade pelo sentido inclui levar em conta em quais condições a enunciação e a leitura estão sendo elaboradas e postas em funcionamento.

Sendo assim, por nosso turno, intentamos deslocar Pêcheux para uma leitura em diálogo com a rede de pensamento construída por Derrida. Acreditamos, também, que o manejo interpretativo da literatura concordando com a citação anterior - oferece possibilidades importantes para analisar a atualização discursiva das enunciações. Articulando com Nascimento (2001), considerar uma leitura indiciária como essa, em que a ideia de verdade/sentido só pode atuar enquanto rastro, não como presença absoluta, significa abrir a possibilidade do "ler com"; em outras palavras, implica aceitar que os sentidos se colocam em movimento, sem criar novas hierarquias, a partir do jogo relacional com outros contextos e condições de legibilidade.

Rodrigues (2013b), lendo "com" Derrida, traz o "pensamento do feminino" como importante elemento para nos fazer pensar outras formas de considerar a língua e a linguagem. Derrida, ao longo das obras mencionadas (2013 e 1971), estabelece como chão de sua crítica o fato de que o pensamento ocidental foi sendo construído tendo alguns pilares como base: a crença na razão como realidade a priori a erigir valores (logocentrismo); a crença na presença da voz como metáfora do sujeito presente a si e em si mesmo, como elemento da verdade/sentido a garantir estabilidade ao "real" (fonocentrismo); a crença na associação de certos valores tidos como superiores dentro de uma hierarquia na qual o masculino há muito deixou de se traduzir como "pura anatomia" e se colocar como manifestação da verdade como dominação e subordinação do outro (falocentrismo). Estaríamos diante, portanto, de um pensamento do masculino, no qual o gênero está além da performatividade de corpos e sujeitos, mas consolidando-se como forma de fazer a subjetividade funcionar com aparência de evidência. Assim, a ideia de "centro" deixa de ser interessante, a não ser como instrumento de leitura que permite compreender formas de dominação pela linguagem. As "bordas", "fronteiras", tornam-se mais importantes, neste novo contexto de leitura, justamente porque é onde o procedimento de representação das realidades ocorre: não há núcleo, mas relação. Esta, pensando "com" Pêcheux, não se dá fora da história e da ideologia, oferecendo espessura à língua em uso. Nas palavras de Rodrigues:

Se em Kant o julgamento estético deve ser desinteressado, a questão para Derrida passa a ser saber se eu posso dizer de uma coisa se ela é bela sem ter, intrinsecamente, nada a ver com o interesse que eu carrego ou 
não sobre sua existência. Derrida dirá que este tipo de distinção kantiana - entre o que confere valor à beleza e o que resta externo ao sentido pressupõe um discurso sobre o limite entre o dentro e o fora do objeto artístico. 0 parergon ${ }^{3}$ será então aquilo que embaralha o intrínseco/ extrínseco à obra, é a borda, o limiar instável entre dentro/fora, e não será a moldura de um quadro, como no exemplo da parerga de Kant, mas a indicação de como um discurso da tradição filosófica se organiza também sobre o par dentro/fora, interior/exterior. (2013a, p. 31).

Com isso, o pensamento do feminino seria um pensamento da "sombra" que propõe a leitura do já-dito em novas redes relacionais para apontar os limites da significação e como eles fazem o sentido se mover perpetuamente, contrabalançando a ideia de um centro cuja única opção que restaria aos sujeitos interpelados seria a identificação; a qual, por sua vez, como sabemos com Pêcheux (1988), nunca é plena, sempre havendo espaço e possibilidade para a movência. Um pensamento que existe na diferença que não se estabiliza: pensando assim, ele estaria próximo da desidentificação apontada por Pêcheux (1988), uma vez que, assumindo-se como pensamento da diferença, do rastro, não recua diante da Ideologia, abrindo espaço para uma prática política transformadora, espécie de resistência ao assujeitamento do qual não podemos nos livrar; o que, por outro lado, oferece a chance de criar aberturas provisórias e apontar rupturas no estabelecido pela tradição. Nesse processo, hegemonias e subordinações, forças e dominações são questionadas.

Como nos lembra Rodrigues (2013b), pensar ética e política dentro do horizonte de sentidos negociado por Derrida - que "não quer a filosofia enclausurada nos tribunais, mas, sim, como um 'nômade vagabundo', em

\footnotetext{
${ }_{3}$ Carla Rodrigues, no citado artigo, atualiza discursivamente o parergon como um fora da obra que participa da mesma, um suplemento. Trata-se de uma relação com o problema da origem que atua como borda que embaralha o dentro e o fora, colocando-os como impossível distinção definitiva. Estamos, então, diante de um irredutível da arte, nem sujeito e nem objeto.
}

movimento, sem possibilidade de ficar parado" (ibidem, p. 188) - implica a hospitalidade incondicional com relação à alteridade (o outro como irremediavelmente outro) e a responsabilidade pelo por vir (o trabalho com a linguagem como um permanente trabalho com o indecidível). Portanto, o pensamento do feminino seria a proposta de leitura construída por Derrida na desconstrução:

A maquinaria a que Derrida se refere sustentaria algumas das características desse "sujeito", fundadas, ele lembra, na presença do ser: presença a si, identidade, propriedade, personalidade, ego, consciência, vontade, intencionalidade, liberdade e humanidade. (...) A essas características, Derrida contrapõe a différance, o rastro e a ex-propriação, não como categorias de oposição, mas como quase-conceitos que permitem questionar a presença e abrem espaço para uma afirmatividade que, não tendo o sujeito como referência, colocaria o problema da ética e da política em outros termos, alterando as concepções de direito, moral e justiça. Essa seria uma tarefa por vir. Enfrentá-la implicaria distinguir o chamado "sujeito humano" ou o Dasein de todas as outras formas de relação de si consigo ou com o outro "enquanto tal" (...). 0 pensamento de Derrida põe em causa esse significado transcendental que se afirma num sujeito determinado, que se presentifica como "nós, homens". Dizer que a denúncia do falo-logo-fono-centrismo travessa todo o pensamento da desconstrução é também indicar que a desconstrução pode ser entendida, como proponho aqui, como um pensamento que desestabiliza as certezas da tradição e põe em causa o discurso do sujeito masculino falante presente e garantidor de sentido (ibidem, p. 34).

Assim, "pensar o feminino" dissemina-se às custas de uma importante polissemia: não só pensar o gênero, mas os limites em que se fala dele. Ou seja, trata-se de um procedimento que pensa a própria linguagem que interroga, em que termos ela pode operar, para não acabar, paradoxalmente, reforçando aquilo que questiona. É nesse deslocamento que pretendemos empreender um gesto de leitura sobre $A$ hora da estrela (2017). Graças a trabalhos como o de Gotlib (1995), sabe-se que o conjunto das obras 
ficcionais de Clarice Lispector foi recebendo diversos trabalhos de interpretação, notadamente no que se refere a como a obra opera com a linguagem e a temática da existência; inclusive havendo críticos e leitores que veem nas ficções da autora um aparente distanciamento de questões políticas, por exemplo, ainda que tendo sido escrita, em grande parte, durante a Segunda Guerra e a Ditadura Militar Brasileira. No entanto, à medida que compreendemos alguns recursos mobilizados para fazer a língua funcionar, acreditamos que a obra de Lispector traz, sim, um forte posicionamento político, mas em outros termos: o político da língua.

Aliando questões propostas por Derrida e Pêcheux, analisamos a novela citada pensando que o político se marca fortemente ao levar adiante dispositivos de atualização discursiva que acenam para um processo de desindentificação que não nega as estruturas de funcionamento que o dominam, mas, ao mesmo tempo, por meio do trabalho com a linguagem, tenta abrir brechas que apontam para a ausência de naturalidade do sentido, de um sujeito que fala "dono de si". Além disso, não se trata de uma negação, mas, sim, de uma "redescoberta" de uma fertilidade que pode habitar os dizeres, já que é fundamental "Não esquecer que por enquanto é tempo de morangos" (LISPECTOR, 2017, p. 110). Um dos caminhos para se ler a citada ficção assim, acreditamos, é pela reconsideração da instância da narração enquanto enunciação, na dimensão já discutia anteriormente. Nosso caminho escolhido, então, é ir percorrendo a novela de forma a verificar a legibilidade que estamos entendendo ser possível.

Quando anunciamos a intenção de estudar a argumentação presente ao longo da novela, estamos pensando na constituição de Rodrigo S. M. personificação da voz responsável pela enunciação - enquanto sujeito responsável eticamente por recriar uma série de indagações sobre a existência e a língua na forma de algo aceito como narrativo. De início, na
“Dedicatória do autor (Na verdade Clarice Lispector)" (LISPECTOR, 2017, p. 46), a leitura começa a ser encaminhada da seguinte maneira:

E - e não se esquecer que a estrutura do átomo não é vista mas sabe-se dela. Sei de muita coisa que não vi. E vós também. Não se pode dar uma prova da existência do que é mais verdadeiro, o jeito é acreditar. Acreditar chorando.

Esta história acontece em estado de emergência e de calamidade pública Trata-se de um livro inacabado porque lhe falta a resposta. Resposta esta que espero que alguém no mundo ma dê. Vós? É uma história tecnicolor para ter algum luxo, por Deus, que eu também preciso. Amém para todos nós. (ibidem).

Mesmo havendo uma sinalização de que esta voz corresponderia, "Na verdade", a Clarice Lispector e não a Rodrigo S.M., isso não interessa a nós aqui, já que estamos pensando na posição sujeito que enuncia. Como veremos, tanto a voz atribuída a Lispector quanto a S.M. acabam assumindo a mesma enunciação, já que fazem os sentidos se moverem em processos de identificação e de desidentificação semelhantes: há um movimento de resistência, mas também de reconhecimento da alienação da qual não se pode escapar. Como vemos no trecho anterior, o sujeito, na sua necessária relação com a língua, logo de início, revela sua contradição sem a qual não consegue existir: a constatação de uma "calamidade pública" se dá paralelamente ao desejo pelo "luxo" em interlocução com "Deus". Com isso, aos poucos, esse enunciador vai marcando seu lugar em que o dizer se atualiza: a percepção de certa calamidade dissemina-se enquanto questão social, já que história de uma miserável "preto e branco" e enquanto necessidade de se confortar naquilo que é possível mediante a identificação com o Sujeito Universal que desdobra efeitos de certo "luxo divino", no caso, as cores.

Assim, desde o início da ficção, o caráter inacabado do livro refere-se à ausência de respostas que estabilizem a enunciação, "porque lhe falta a 
resposta". Dessa maneira, a novela tem sua legibilidade construída porque reconhecemos nela elementos atribuídos às diegeses, mas, também, há uma rede argumentativa, de defesa de ponto de vista, que, explícita e paralelamente, se constrói com o narrado. No entanto, tal argumentação estrutura-se, em grande medida, como processo de tentativas de desidentificação. Dizemos “tentativas" porque esse trabalho só é possível de se dar nas bordas da linguagem, já que não há núcleo. A referência da enunciação - a busca por respostas - funciona discursivamente mediante um processo que é inevitavelmente contraditório - entre a identificação e o questionamento desta, a qual não ocorre de fora da formação ideológica e discursiva - mas que, nem por isso, faz a argumentação e o questionamento pararem. Logo, não se trata de um questionamento e de uma busca por respostas "naturais", mediante algum "mistério da vida". Isso seria criar um novo núcleo metafísico de leitura da novela: se há esse movimento, ele ocorre discursivamente entre posições discursivas que se tocam e se repelem mutuamente na constituição de efeitos de sentido. 0 efeito-sujeito, ainda que questionador, se faz às custas de um assujeitamento: um falar de si e da narrativa que ocorre segundo certas condições. Ou seja, tal referência a si e à diegese como algo a ser questionado, duvidado, desestabilizado porque seria fragmentado não ocorre de fora da história, mas sempre recorrendo a certo interdiscurso e de certa posição. Além disso, por mais que se percebam efeitos de uma narrativa que tenta dialogar com outros gêneros discursivos, tal prática ocorre com certa limitação. Caso contrário, se houvesse e fosse possível uma total "transformação" da diegese, a leitura ficaria impossibilitada:

(...) a referência discursiva do objeto já é constituída em formações discursivas (técnicas, morais, políticas...) que combinam seus efeitos em efeitos de interdiscurso. Não haveria assim naturalidade "técnica" do balão livre ou da estrada de ferro, ou naturalidade "zoológica" da toupeira, que seria em seguida objeto de metáforas literárias ou políticas; a produção discursiva desses objetos "circularia" entre diferentes regiões discursivas, das quais nenhuma pode ser considerada originária (PÊCHEUX 2011, p. 158).

Há a elaboração de uma argumentação que atua, inclusive, na desestabilização do que se espera de uma narrativa, uma ficção. A materialidade discursiva, funcionando na relação entre imaginário e real, desloca sentidos aceitos como "originais", mas a partir de algo estabilizado pela repetição que permite isso. Por isso, o questionamento do gênero narrativo ocorre, tropeçando, de dentro e de fora deste, no limite. As paráfrases recorrentes na narrativa apontam transferências, metáforas, que atuam em relação a certa posição mediante a memória. Este processo, pela atividade mencionada, é individual e social na enunciação da novela, sendo possível porque algo já foi dito em outro tempo e lugar:

A paráfrase e a metáfora explicitam-se, pois, enquanto procedimentos de análise. Esta é, para mim, uma marca da especificidade da análise de discurso: ela introduz uma noção não linguística de paráfrase e uma noção de metáfora que não deriva da retórica, ou dos estudos literários, assim como uma noção de "memória" que tem suas determinações que não são psicológicas, cronológicas etc. A relação entre essas noções e o modo de procedimento da análise de discurso, ligando o que é estabilizado e o que é sujeito a equívoco, no movimento da descrição e da interpretação vai marcar profundamente os estudos da linguagem (ORLANDI, 2003, p. 5).

Pensando "com" Orlandi (2004), a enunciação de A hora da estrela elabora sua narratividade " como a maneira pela qual uma memória se diz em processos identitários apoiados em modos de individuação do sujeito,

${ }^{4}$ Todo gênero narrativo, portanto, só é possível - de um ponto de vista discursivo - graças à elaboração poder dizer. Essa atividade só é possibilitada porque ele se inscreve na memória no já-dito para repetiç̃o e individuacão: esse movimento lhe confere como dissemos, não tomamos como sinônimos). 
afirmando/vinculando (seu 'pertencimento') sua existência a espaços de interpretação determinados, consoantes a" (ibidem, p. 79). Portanto, o sujeito enunciador extrapola o gênero narrativo canônico e o pensamento falo-logo-fono-cêntrico, mas somente por referência e identificação discursivas "a" eles, os quais atuam como exterioridade constitutiva dos dizeres que circulam na obra, seja pela nomeação como Clarice ou Rodrigo.

Daí, atualizamos tal funcionamento pela nomeação de "expectativa semiótica": um enunciar e uma legibilidade só se fazem possíveis porque há, de alguma forma, uma base esperada construída alhures. Portanto, pensar essa "expectativa semiótica" da novela de Lispector implica um duplo gesto em relação à herança (DERRIDA, 2004), de forma que o enunciar - como exemplificamos no trecho anterior da narrativa - sofre uma violência oculta nessa herança da memória interdiscursiva. Inclusive, pensamos a relação entre os termos "identificação" e "DESidentificação" não só como processo de acréscimo de prefixo de um a outro, mas pela via de que o segundo termo carrega inevitavelmente o outro em si: não há este movimento sem aquele. Derrida, em "La loi du genre" (1986), propõe justamente que o dentro não se sustenta sem um fora, sendo necessário levar em conta os termos nos e pelos quais se advoga uma norma de leitura, um reconhecimento. Porque transita entre dentro e fora, identificação e desidentificação, o enunciador de $A$ hora da estrela precisa argumentar, tornando-se responsável (o que significa reconhecer a posição "de luxo" de onde fala) diante da herança, do interdiscurso, que recebe:

Uma vez por outro tinha a sorte de ouvir de madrugada um galo cantar a vida e ela se lembrava nostálgica do sertão. Onde caberia um galo a cocoricar naquelas paragens ressequidas de artigos por atacado de exportação e importação? (Se o leitor possui alguma riqueza e vida bem acomodada, sairá de si para ver como é às vezes o outro. Se é pobre, não estará me lendo porque ler-me é supérfluo para quem tem uma leve fome permanente. Faço aqui o papel de vossa válvula de escape e da vida massacrante da média burguesia. Bem sei que é assustador sair de si mesmo, mas tudo o que é novo assusta. Embora a moça anônima da história seja tão antiga que podia ser uma figura bíblica. Ela era subterrânea e nunca tinha floração. Minto: ela era capim.) (LISPECTOR, 2017, p. 63, grifos nossos).

Este trecho ajuda-nos a exemplificar este processo de trabalho nas bordas de que temos falado. Quando falamos em atividade argumentativa do enunciador de $A$ hora da estrela, estamos pensando para além da questão retórica, mas em uma leitura indiciária na qual tentamos ler a relação com o discurso materializado no uso da língua. No caso da novela, entendemos que tal prática é colocada em funcionamento, revelando a contradição de um enunciador que busca romper com o já-dado de sua classe social, média e/ou burguesa (citadas por eles, inclusive); no entanto, o faz impossibilitado de se livrar do mesmo, uma vez que também constituído por ele. Vejamos, por exemplo, que, no trecho anterior, há um uso repetitivo de artigos definidos antes de alguns nomes, como "média burguesia" e "moça anônima". Estamos diante de um uso que lemos não só no sentido gramatical de determinação do termo subsequente: vislumbramos, aí, um ato politicamente marcado, uma vez que se trata de efeitos de "classe média" e de "anonimato" e "pobreza" que estão sendo postos em circulação, dado que os sentidos não são literais e não podem ser generalizados, a não ser como inscrição em dada formação ideológica. Com isso, a enunciação desloca sentidos em um efeito metafórico, argumentando por meio de descrições como "ela era subterrânea", "ela era capim", para falar de uma forma de pobreza, a qual é posta em circulação com relação a um outro posto nos enunciados, a "média burguesia", com a qual o enunciador se identifica para, em seguida, tentar abrir brechas na língua, apontando para a constituição contraditória não só da linguagem, mas dos sujeitos que dizem. Trata-se de um estranhamento 
que só pode ser vislumbrado pelos usos da língua na perspectiva que estamos adotando. Isso vemos, também, em:

A datilógrafa vivia numa espécie de atordoado nimbo, entre céu e inferno. Nunca pensara em "eu sou eu". Acho que julgava não ter direito, ela era um acaso. Um feto jogado na lata de lixo embrulhado em um jornal. Há milhares como ela? Sim, e que são apenas um acaso. Pensando bem: quem não é apenas um acaso na vida? Quanto a mim, só me livro de ser apenas um acaso porque escrevo, o que é um ato que é um fato. (...) Para que escrevo? E eu sei? Sei não. Sim, é verdade, às vezes também penso que não sou eu, pareço pertencer a uma galáxia longínqua de tão estranho que sou de mim. Sou eu? Espanto-me com o meu encontro (LISPECTOR, 2017, p. 68).

A construção de argumentos - como os destacados no trecho - não se dá em uma perspectiva logocêntrica: o que ocorre é uma argumentação pelas "sombras", fazendo vacilar - pela via da contradição que faz padecer o enunciador diante da pobreza que cria para poder falar - o que parecia estabelecido. Nessa relação entre as classes, criam-se efeitos de "pobreza" e "miséria" que não estão somente em Macabéa, mas também na atividade da língua na enunciação e na (im)possibilidade de construção de alguma identidade para Rodrigo S.M. Mesmo este dizendo que "Há milhares como ela", isso atua como efeito de convencimento de quem lê, já que, na verdade, esta datilógrafa-capim-feto-jogada-no-lixo ganha materialidade na enunciação desta novela especificamente. Esta, por sua vez, dá efeitos de generalidade a ela - como se "estivesse aí, no mundo, aos milhares" quando só existe por relação à instância que diz e apresenta a realidade de que fala.

Portanto, a representação funciona à medida que cria continuidades - recuperando a memória interdiscursiva sobre pobreza e riqueza, por exemplo - e descontinuidades - um enunciador que se posiciona, tentando demonstrar os tropeços onde a fala falha. Afinal, sendo "acaso", não há nada pronto em dada realidade para se apropriar; no entanto, um contínuo inscrever-se na memória, desdobrando-a em efeitos materialmente elaborados. Quando afirma não haver finalidade para a escrita, ela se torna possibilidade de existência, uma vez que os efeitos do dizer são sempre ulteriores, incontornáveis e não previsíveis: encontro com o estranho, real da história.

Como propõe Derrida (2004), todos são responsáveis pela herança, já que não pode ser recusada. Paradoxalmente: deve-se reafirmar o que veio antes e ser fiel a isso, o que não significa copiar, mas responder ao que nos antecede e constitui, transformando, recriando. 0 enunciador, na dificuldade de transformar a sua condição e a da personagem, atua na linguagem e no gênero discursivo escolhido para poder dizer. Assim, o gênero narrativo corresponde mais a um desejo de "como fazer" do que a uma ordem, uma normatividade. No entanto, para poder dizer, isso só pode ter início na língua e nos gêneros do outro; por outro lado, não há margem exata que separa identidades e alteridades, de forma que tudo só pode ser parcialmente concretizado, o que afeta o dizer e o ler. Justamente isso pode ser usado para colocar sentidos em movimento e gêneros em transformação: a primeira lei do gênero é justamente perguntar o que lhe determina a si mesmo, o que o legaliza (DERRIDA, 1986). Por ser frágil, precário, já que vive às custas de repetição, é que se abre espaço à desestabilização. Vejamos:

(Mas e eu? E eu que estou contando esta história que nunca me aconteceu e nem a ninguém que eu conheça? Fico abismado por saber tanto a verdade. Será que meu ofício doloroso é o de adivinhar na carne a verdade que ninguém quer enxergar? Se sei quase tudo de Macabéa é que já peguei de relance o olhar de uma nordestina amarelada. Esse relance me deu ela de corpo inteiro. Quanto ao paraibano, na certa devo ter-lhe fotografado mentalmente a cara - e quando se presta atenção a cara diz quase tudo.)

E agora apago-me de novo e volto para essas duas pessoas que por força das circunstâncias eram seres meio abstratos (LISPECTOR, 2017, p. 85). 
Usando o trecho acima como diálogo "com" nossa reflexão, o enunciador traz, pela constituição de uma argumentação "fal(h)ada" o questionamento da lei que permite narrativa, ele e as personagens - tudo em suas supostas (in)verdades - ganharem existência. Por outro lado, o próprio uso de parênteses pode indicar, como efeito, uma abertura (inclusive gráfica) na diegese que parece ir acontecendo ao mesmo tempo em que as bases dela são questionadas. Além disso, outros elementos de textualidade, como a coesão entre os parágrafos (a qual não é explícita, como, por exemplo, por uso de conjunções), vão ganhando possibilidades de leitura à medida que são recursos que se repetem e configuram certo estilo à novela de Lispector. Isso quer dizer que é construído um jogo de coerência relativizando o "dentro" e o "fora", como no trecho anterior: afirma-se conhecer a verdade, mas os parênteses são de interrogação; apaga-se a si, que "se advinha na carne", para surgir o outro, abstrato; "história que nunca aconteceu" como forte acontecimento discursivo; "relances" que se dão por meio de "corpo inteiro".

Em outros termos, a tentativa de reflexão, de argumentação, elaborada pelo sujeito que enuncia ganha força em uma desrealização das certezas. Afirma-se saber a verdade, mas em um contexto citacional e de desidentificação que faz com que os efeitos do que ela seja - a verdade - só possam ser violentamente outros, espécie de hospitalidade incondicional à alteridade, pensamento do feminino. Ou seja, não há chegada ou passagem definitivas, mas um constante devir irrepresentável, já que só pode ganhar expressão por meio do já-dito que se move entre as posições discursivas (a da classe média e outra que busca construir sobre a pobreza de Macabéa, por exemplo). Uma argumentação que, tentando se assumir contraditória, parece mimetizar o que sugere ser o movimento dos discursos e dos sentidos: afirma-se "grávido de" parênteses que só podem questionar o que lhes antecedem e o que lhes sucedem, não havendo espaço para a voz imperativa. Talvez, por isso, conforme afirma o enunciador, estamos diante de um livro sem fim. Livro este que pode ser narrativa e ensaio e diário e anotações esparsas: enfim, abertura, já que opera enquanto hiância que retira e coloca âncoras em gêneros discursivos não para se prender, mas fazer (não) ler um outro, escapando de si mesmo, arbitrariedade que se exerce com efeitos de obviedade.

Dessa forma, a argumentatividade (potência que se realiza na legibilidade que criamos neste artigo como gesto de leitura) elaborada em A hora da estrela - naquilo que entendemos como ação do pensamento do feminino - ajuda-nos a atualizar o que Rosenfeld (1969) nomeou como desrealização do romance moderno. Dizemos isso porque - à luz da relação entre propostas de Pêcheux e de Derrida - o fenômeno citado expande-se se levarmos em conta o modelo ocidental hegemônico de pensamento e a materialidade histórico-ideológica do sentido. Além disso, a "DESrealização" (que, na formação morfológica, traz, dentro de si, "o" "real") é possível sempre com vistas a alguma manifestação de realidade que se acredita atingir, falar sobre, questionar. Quando o enunciador da novela interroga "sua" verdade e "seu" real (que lhe pertencem por despossessão necessária, uma vez que marcados pela contradição de serem indecidivelmente individuais "e" coletivos), o faz a partir de rastros do que acredita que estes sejam ou não. Isso só funciona dentro de uma formação discursiva ou um interdiscurso que oferece já-ditos para identificação, mas, paradoxalmente (como o que é do âmbito da ideologia), também para desindentificação.

É melhor eu não falar em felicidade ou infelicidade - provoca aquela saudade desmaiada e lilás, aquele perfume de violeta, as águas geladas da maré mansa em espumas pela areia. Eu não quero provocar porque dói.

Macabéa, esqueci de dizer, tinha uma infelicidade: era sensual. Como é que num corpo cariado como o dela cabia tanta lascívia, sem que ela soubesse que tinha? Mistério (LISPECTOR, 2017, p. 88). 
A construção de uma argumentação a parecer funcionar é necessária justamente porque um pensamento de desconstrução se faz a partir de um outro que lhe fornece bases para existir, mas não como algo de fora, mas de dentro. As metáforas do trecho supracitado ganham efeito de estranheza, dentre outros motivos, por sua ação discursiva. Seu efeito de indecidível "É melhor eu não falar em felicidade ou infelicidade" - opera pelo silêncio constituinte na relação entre termos que, na descrição de uma felicidade, talvez não sejam esperados em uma "expectativa semiótica" que se repete nos enunciados sobre "ser feliz". Entendendo que isso não pode ser descrito facilmente, o enunciador associa cores, cheiros e tato, provocando como efeitos o excesso, a saturação, que só são percebidos porque, no processo de enunciação e leitura, evoca-se uma ideia histórica e ideologicamente consolidada e que circula sobre o "ser feliz": "ser" verbal e substantivo, que não se detém em um ou outro. Além disso, a suposta "sensualidade" de Macabéa - enunciada e lida a partir de posicionamentos específicos ganha ares de violência e não de qualidade de valoração positiva, uma vez que acontece como algo sem fundamento, cujo mistério atua como resto de sentido irrepresentável, relacionado ética e estética como lugar totalmente outro, no qual o sentido surge (pela evocação de uma memória social do que é "ser" sensual) e desaparece (porque é mistério e sem explicação em um corpo inapto para a vida da enunciação que o convoca a re-existir, pura differánce ${ }^{5}$ ). Com isso, não há uma incompletude que exista "em si" e que foi descoberta pelo enunciador (sujeito e objeto da enunciação), mas um suplemento que se atualiza mediante uma nova relação com a origem, o sentido, a narrativa e a verdade.

${ }^{5}$ Não nos esquecendo de que a differánce surge como operador de leitura - quase-conceito derridiano que aponta para o sentido, cujo caráter de funcionamento é estar e não estar, paradoxalmente, para que se abra espaço para o sujeito que se utiliza da linguagem para existir na leitura e na enunciação. Não é possível, então, usar significados dados, literais, prontos ao uso: o que existe são rastros cuja existência resiste na memória que apaga para poder lembrar, em nova rede de significações e relações.
Saiu de casa da cartomante aos tropeços e parou no beco escurecido pelo crepúsculo - crepúsculo que é hora de ninguém. Mas ela de olhos ofuscados como se o último final da tarde fosse mancha de sangue e ouro quase negro. Tanta riqueza de atmosfera e recebeu o primeiro esgar da noite que, sim, sim, era funda e faustosa. Macabéa ficou um pouco aturdida sem saber se atravessaria a rua pois sua vida já estava mudada. E mudada por palavras - desde Moisés se sabe que a palavra é divina. Até para atravessar a rua ela já era outra pessoa. Uma pessoa grávida de futuro. Sentia em si uma esperança tão violenta como jamais sentira tamanho desespero. Se ela não era mais ela mesma, isso significava uma perda que valia por um ganho. Assim como havia sentença de morte, a cartomante lhe decretara sentença de vida. Tudo de repente era muito e muito e tão amplo que ela sentiu vontade de chorar. Mas não chorou: seus olhos faiscavam como o sol que morria (LISPECTOR, 20017, p. 104).

O trecho anterior antecede aquilo que é nomeado como "a hora da estrela" de Macabéa: sua morte por atropelamento. A ironia atua pela articulação de expectativas de vida violenta e velozmente convertidas em morte, perturbando fronteiras entre uma e outra, já que, ali, parece nascer a atração dos demais passantes pela personagem, "uma resistente raça anã teimosa que um dia vai talvez reivindicar o direito ao grito" (ibidem). Os deslocamentos construídos - entre vida e morte, perda e ganho, esperança e violência - e postos em funcionamento se dão por e na língua, embaralhando as ideias sobre vida e morte, e a suposta ordem e valores em que elas existiriam, uma vez que, na enunciação, a representação perde sua estabilidade junto com o que vai sendo descrito, em que tudo "morre" para "viver" de novo, mas em outros contextos. 0 que sobra é um rastro do que é possível surgir como efeito de sentido, disseminado (como "mancha de sangue e ouro quase negro") na argumentação sobre o que é (im)possível nesta narrativa. A materialidade da pobreza existencial de Macabéa, criada por inscrição em certa formação discursiva em que circulam dizeres sobre "ser" pobre, é liberada para significar em outras possibilidades (como vida leve que voa quando atropelada pelo carro importado; pela vida pobre 
também pela falta de condições de se determinar por completo; como vida pobre pelos adjetivos que lhe faltam etc).

Por fim, falar em argumentação e enunciação em $A$ hora da estrela, discursivamente, à nossa compreensão, surge como reconhecimento de uma prática política na escritura de Clarice Lispector, cujo funcionamento opera nas bordas, misturando o evidente e o silêncio ${ }^{6}$ que separa, une e faz viver sentidos. Isso significa que o político, aqui, pode ser vislumbrado na busca de uma significação outra para a língua (logo, para a existência) que se debate, também, com a ausência de possibilidade de não se identificar, ao menos um pouco, com o que se quer rejeitar: irrepresentável que nos chega pelas mãos de um simbólico caduco, fal(h)o e cheio de tropeços. Não se trata de resignação, mas de fazer funcionar suplementos naquilo que parece sem saída. Nessa (falta de) direção de sentido, nomear um conjunto de enunciados - aceitos e lidos em formas de certos gêneros discursivos como "a hora da estrela" talvez possa sinalizar para o efeito de rastro: da mesma forma que só podemos ver, no céu que se contempla de um lugar, a luz de estrelas que já brilharam em outro tempo e espaço; no que diz respeito à língua - abismo de significantes - o sentido só pode nos chegar como vestígio, índice do já dito em outra "hora" e outra "estrela".

\section{Referências}

DERRIDA, Jacques. A escritura e a diferença. São Paulo: Perspectiva, 1971. DERRIDA, Jacques. La loi du genre. In: DERRIDA, Jacques. Parages. Paris: Galilée, 1986. DERRIDA, Jacques. A farmácia de Platão. São Paulo: Iluminuras, 1997.

DERRIDA, Jacques. Gramatologia. São Paulo: Perspectiva, 2013.

DERRIDA Jacques; ROUDINESCO, Elisabeth. De que amanhã... Rio de Janeiro: Jorge Zahar Editor, 2004

6 Sobre a direção de sentidos a respeito do que entendemos por "silêncio", sugerimos o trabalho de Eni Orlandi (2007)
GENETTE, Gerard. Discurso da narrativa. Lisboa: Vega. s.d. GOTLIB, Nádia Battella. Clarice - uma vida que se conta. Editora Ática, 1995. Lispector, Clarice. A hora da estrela. Rio de Janeiro: Rocco, 2017.

GRIGOLETTO, Evandra. Do lugar social ao discursivo: o imbricamento de diferentes posições sujeito. In: Seminário de Estudos em Análise do Discurso UFRGS, 2005 Porto Alegre. Anais eletrônicos...Porto Alegre: UFRGS, 2005. p. 154-164. Disponível em: <mhttp://www.ufrgs.br/analisedodiscurso/anaisdosead/2SEAD/SIMPOSIOS/ EvandraGrigoletto.pdf>. Acesso em: 08 fev. 2018.

LAGAZZI, S. O desafio de dizer não. Campinas: Pontes, 1988.

NASCIMENTO, Evando. Derrida e a literatura. Niteroi: EDUFF, 2001.

ORLANDI, Eni Puccinelli. Análise de discurso: princípios e procedimentos. Campinas: Pontes, 2000.

ORLANDI, Eni Puccinelli. A Análise de discurso em suas diferentes tradições intelectuais: o Brasil. In: SEMINÁRIO DE ESTUDOS EM ANÁLISE DE DISCURSO, 1., 2003, Porto Alegre. Anais do... Porto Alegre (RS): UFRGS, 2003

ORLANDI, Eni Puccinelli. As formas do silêncio: no movimento dos sentidos. 6. ed. Campinas: Editora da Unicamp, 2007.

ORLANDI, Eni Puccinelli. Parkour: corpo e espaço reescrevem o sujeito. In: Revista Língua e Instrumentos Linguísticos. Campinas-SP, no 34-jul-dez, 2014.

PÊCHEUX, Michel. Semântica e discurso: uma crítica à afirmação do óbvio. Campinas: Pontes, 1988.

ORLANDI, Eni Puccinelli. Metáfora e Interdiscurso. In: ORLANDI, Eni Puccinelli (Org.). Análise de Discurso - Michel Pêcheux. Campinas: Pontes Editores, 2011.

RODRIGUES, Carla. A literatura entre Derrida e Lacan: dentro/fora das relações de poder. Viso: Cadernos de Estética Aplicada, v. 13, s/n, 2013a.

RODRIGUES, Carla. Duas palavras para o feminino: hospitalidade e responsabilidade. Sobre ética e política em Jacques Derrida. Rio de Janeiro: NAU Editora/Faperj, 2013b.

ROSENFELD, A. Reflexões sobre o romance moderno. In: ROSENFELD, A. Texto/contexto. São Paulo: Perspectiva, 1969.

Recebido em 25/04/2018

Aceito em $02 / 10 / 2018$ 